\title{
Complement Activation in Newborn Infants with Early Onset Infection
}

\author{
GERTRUD ZILOW, EUGEN P. ZILOW, REINHARD BURGER, AND OTWIN LINDERKAMP
}

Institute of Immunology and Division of Neonatology: University of Heidelberg, 6900 Heidelberg; and Robert Koch-Institute, Bündesgesundheitsamt, 1000 Berlin 65, Germany

\begin{abstract}
The complement system is an important element in host defense. Quantitative deficiencies of total hemolytic complement activity and decreased C3 levels were reported in sera from normal neonates. However, little is known about complement activation products in the newborn. In a prospective study, complement activation products were determined in 32 healthy term neonates, in 41 neonates with colonization of their mothers, in 15 colonized neonates, and in 10 neonates with early onset infection. In all newborns, EDTA plasma was obtained within the first $6 \mathrm{~h}$ of life. The anaphylatoxin C3a-desArg was determined with a novel ELISA using an MAb reacting with a neoepitope of $\mathrm{C} 3 \mathrm{a}$-desArg. $\mathrm{C} 3 \mathrm{bBbP}$ (alternative pathway convertase) and $\mathrm{Cl}$ rsC1-inactivator (activation product of classical pathway) were measured with doublesandwich ELISA. C3 was determined by radial immunodiffusion. Plasma concentrations of C3a-desArg were similar in healthy term neonates and healthy adults, whereas diminished $\mathrm{C} 3$ levels were observed in the newborn infants. There were no significant differences between healthy neonates, neonates with colonized mothers, and colonized neonates. In neonates with infection, a significant elevation of C3a-desArg was found at the onset of the disease, resulting from alternative pathway activation. In contrast, the C1rsCl-inactivator complex showed no significant differences among healthy, colonized, and infected neonates. The anaphylatoxin $\mathrm{C3a}$ mediates inflammatory reactions such as vasodilatation and an increase in microvascular permeability and might therefore play an important role in severe neonatal infection. (Pediatr Res 34: 199-203, 1993)
\end{abstract}

\section{Abbreviations}

GBS, group B streptococcus

CH50, total hemolytic complement activity

APH50, alternative pathway hemolytic activity

CRP, C-reactive protein

The complement system is an important effector system in the inflammatory process and an essential component of host defense mechanisms. Studies of patients with genetic defects of individual complement components have helped to elucidate the contribution of complement to various immunologic defense mechanisms. Most patients with a selective deficiency of certain components suffer from recurrent infections $(1,2)$. Neonates have a relative deficiency of most complement components in comparison with adults (3-5). These deficiencies are thought to result from inadequate synthesis by the fetus $(6,7)$. The increased

Received July 28, 1992; accepted March 16, 1993.

Correspondence: Dr. Gertrud Zilow. Institute of Immunology. University of Heidelberg. Im Neuenheimer Feld 305, 6900 Heidelberg. Germany. incidence of infection in newborn infants has been related to these relative deficiencies, because complement is known to participate in the defense against bacterial and viral infections. The anaphylatoxins $\mathrm{C} 3 \mathrm{a}, \mathrm{C4a}$, and $\mathrm{C5a}$ are known to mediate a series of biologic events. They induce histamine release from mast cells and basophils, cause aggregation of granulocytes with subsequent enzyme liberation, and stimulate leukotriene synthesis $(8,9)$. Immune adherence, opsonization, leukocyte chemotaxis, and virus neutralization depend on activation of the complement system. In spite of this biologic importance, there are only a few studies on the complement system in the newborn infant. Studies on complement in newborn infants have shown a decreased concentration of the native proteins and low $\mathrm{CH} 50$ and APH50 activities compared with adults (10-13). There is little information in neonates about activation products of the complement cascade. Two recent studies report C3d levels (one of the final split products of $\mathrm{C} 3$ ) in newborn infants with infection $(14,15)$.

The purpose of this study was to investigate activation of the complement system in the newborn infant to establish normal values for the activation products $\mathrm{C} 3 \mathrm{a}$-desArg, C3bBbP, and $\mathrm{Cl}$ rsCl-inactivator and to determine their changes in infection of the neonate. C3a-desArg is generated by cleavage of C3. $\mathrm{C} 3 \mathrm{bBbP}$ is an indicator of the alternative pathway activation (16), and $\mathrm{Cl}$ rsCl-inactivator is an indicator of classical pathway activation (17).

\section{MATERIALS AND METHODS}

Patients. Blood samples from 98 newborn infants were studied with the approval of the Department of Pediatrics Human Subjects Research Committee. Gestational age was derived from maternal history and confirmed by clinical assessment of maturity (18). Cultures of vagina and rectum to detect GBS were taken from all mothers during the last $10 \mathrm{wk}$ of pregnancy. In the neonates, material for bacterial cultures was taken from the external ear and from gastric aspirate within the Ist h of life. Tracheal aspirates were taken from intubated infants. Clinical specimens were collected and inoculated onto the surface of GBS agar (19). In cases of premature rupture of the membranes or suspected maternal infection (fever, elevated CRP, leukocytosis), prenatal vaginal swabs and urine samples were also processed on chocolate and MacConkey agar for both gram-negative and gram-positive bacteria. Blood cultures were collected using the BCB system Liquoid Blood Culture Bottle BHI-S (F. HoffmannLa Roche AG, Basel, Switzerland). Thirty-two healthy neonates with gestational age between 36 and 42 wk and birth weight between 2500 and $4020 \mathrm{~g}$ were included in this study. Neither the mothers nor the infants were colonized with GBS or other potentially pathogenic bacteria, which had within the last few years been found to be the predominant pathogens for early onset neonatal sepsis in our perinatal care center. Forty-one healthy infants had mothers who were colonized with GBS. Fifteen newborns were colonized with GBS or gram-negative 
bacterial pathogens. Ten neonates had a severe early-onset infection with clinical manifestation at the 1 st $\mathrm{d}$ of life. The predominant clinical signs of infection were: respiratory distress, apnea, bradycardia, hypotonia, irritability or lethargy, and impaired peripheral circulation. All the babies had two or more of the described clinical signs. All the babies developed CRP values $\geq 20 \mathrm{mg} / \mathrm{L}$ within the first $48 \mathrm{~h}$ of life. Nine of 10 babies suffered from culture-proven septicemia (Table 1). One baby suffered from severe congenital pneumonia that led to ventilator-dependent respiratory distress. The focal infection was proven by the detection of GBS in the tracheal aspirate taken after intubation immediately after delivery. None of the babies suffered from perinatal asphyxia.

Plasma samples. EDTA plasma was obtained in all neonates within the first $6 \mathrm{~h}$ of life and frozen immediately at $-70^{\circ} \mathrm{C}$ until assayed. Normal values for adults were obtained from healthy blood donors of the Blood Bank of the University of Heidelberg.

Measurement of complement proteins. Concentration of plasma $\mathrm{C} 3$ was determined by radial immunodiffusion (Behring Diagnostics, Frankfurt, Germany). C3a-desArg was quantitated as previously described (20). Briefly, wells of polystyrene microtiter plates (Nunc, Roskilde, Denmark) were incubated with 100 $\mu \mathrm{L}$ of purified MAb H466 $(10 \mu \mathrm{g} / \mathrm{mL})$ in $0.01 \mathrm{M}$ sodium phosphate, $0.15 \mathrm{M} \mathrm{NaCl}$, pH 7.4 (buffer A). This capture antibody $\mathrm{H} 466$ reacts specifically with a neoantigenic determinant of $\mathrm{C} 3 \mathrm{a}$ and does not recognize the uncleaved $\mathrm{C} 3$ molecule $(21)$. Therefore, separation of C3a-desArg from C3 in the plasma sample before the assay was not necessary. After blocking of the remaining nonspecific binding sites with $0.5 \%$ casein (Merck, Darmstadt, Germany) in buffer $A\left(1 \mathrm{~h}, 37^{\circ} \mathrm{C}\right)$, the patient sample ( $100 \mu \mathrm{L}$, diluted $1: 100$ in buffer A containing $0.25 \%$ casein, 0.01 $M$ EDTA, $0.05 \%$ Tween 20 ) was added and incubated for $1 \mathrm{~h}$ at room temperature. Bound C3a-desArg was detected by incubation with the second peroxidase-labeled MAb H13 (22) followed by $100 \mu \mathrm{L} /$ well of the peroxidase substrate ortho-phenylenediamine dihydrochloride (Dakopatts, Hamburg, Germany) in 0.1 $\mathrm{M}$ citric acid-phosphate buffer $\mathrm{pH} 5$. The reaction was stopped after 5 min with $12.5 \% \mathrm{H}_{2} \mathrm{SO}_{4}(50 \mu \mathrm{L})$ and the $\mathrm{OD}$ measured by an ELISA reader (Easy Reader, SLT Labinstruments, Salzburg, Austria). C3a-desArg concentrations in the plasma samples were calculated from a calibration curve using different concentrations of purified C3a-desArg in EDTA plasma.

The complex $\mathrm{C} 3 \mathrm{bBbP}$ was quantitated in a double-sandwich ELISA system (23) using $50 \mu \mathrm{L}$ of goat anti-human P (Atlantic antibodies, Baxter, Unterschleißheim, Germany) as capture antibody diluted 1:300 in buffer $A$. The remaining nonspecific binding sites were blocked with buffer A containing $0.25 \%$ BSA (buffer B, 2 h, room temperature). Fifty $\mu \mathrm{L}$ of patients' samples diluted 1:25 in sample buffer (buffer A containing $0.25 \%$ BSA, $0.01 \%$ EDTA, $0.05 \%$ Tween 20 ) were added and incubated (1 $\mathrm{h}$, room temperature). Bound C3bBbP was detected with biotinylated anti-human C3c (Dakopatts) diluted 1:300 in buffer A,
$0.05 \%$ Tween 20. Incubation with streptavidin-peroxidase (Amersham, Braunschweig. Germany) followed, and orthophenylenediamine dihydrochloride was used as substrate. The reaction was stopped with $12.5 \% \mathrm{H}_{2} \mathrm{SO}_{4}$, and $\mathrm{OD}$ was read at $490 \mathrm{~nm}$. C3bBbP complex $(\mathrm{U} / \mathrm{mL})$ was calculated by reference to a standard curve obtained with serial dilutions of inulinactivated normal human serum. Quantitation of the $\mathrm{Cl}$ rsC1inactivator complex (ClrsClina) (23) was done with rabbit antihuman C1-inactivator (Dakopatts) as capture antibody (1:100 in buffer A). After saturation of the plates with buffer B, plasma samples (diluted 1:500 in sample buffer) were added and incubated $1 \mathrm{~h}$ at room temperature. Goat anti-human Cls (Atlantic Antibodies, Baxter) diluted 1:500 in sample buffer was used as second antibody followed by peroxidase-labeled rabbit anti-goat IgG (Dianova, Hamburg, Germany; 1:500 in buffer B). 2,2'azinobis(3-ethylbenzthiazolinesulfonic acid) was used as substrate. The reaction was stopped with $0.2 \mathrm{M}$ oxalic acid, and OD was read at $405 \mathrm{~nm}$. Values were expressed as $U / \mathrm{mL}$ calculated by reference to a standard curve obtained with IgG-activated normal human serum. Each incubation step was followed by washing three times with buffer A containing $0.05 \%$ Tween 20 .

All assays on complement activation products were done in duplicate, and a maximum of within-sample variance of $10 \%$ was accepted.

Statistical analyses. The significance of intergroup differences was assessed by the Mann-Whitney U-test. Statistically significant differences were accepted at $p<0.05$. Data are expressed as median and range in the tables.

\section{RESULTS}

Table 2 shows that $\mathrm{C} 3$ levels were similar in the four groups of neonates. This indicates that C3 was not affected by GBS colonization or septicemia. Healthy adults show $\mathrm{C} 3$ values of 0.8 to $1.2 \mathrm{~g} / \mathrm{L}$.

There were no significant differences in C3a-desArg levels between healthy newborn infants $(177 \pm 101 \mu \mathrm{g} / \mathrm{L})$ and a control group of normal adults $(171 \pm 76 \mu \mathrm{g} / \mathrm{L})$. Colonization of the mother or of the infant with GBS did not significantly affect C3a-desArg in the neonates. Three $(9.4 \%)$ of the 32 healthy newborn infants (group I) had C3a-desArg levels $>280 \mu \mathrm{g} / \mathrm{L}$ (mean \pm 1 SD). Five of the 41 newborn infants $(12.2 \%)$ with colonized mothers (group II) and three of the 15 infants $(20 \%)$ who were colonized themselves (group III) had C3a-desArg $>280$ $\mu \mathrm{g} / \mathrm{L}$. In the infants with proven bacterial infection, an initial significant increase in C3a-desArg concentration was observed. Only one septic patient (patient 7 in Table 2) had a C3a-desArg level $<280 \mu \mathrm{g} / \mathrm{L}$. One neonate with a 10 -fold elevation of C3adesArg had severe early-onset infection.

Table 2 shows the complement activation products $\mathrm{C} 3 \mathrm{bBbP}$ (indicator of alternative pathway activation) and $\mathrm{Cl}$ rsCl-inactivator (indicator of classical pathway activation) in the four

Table 1. Bacteria, culture sites, and maternal history of 10 infants with early-onset infection

\begin{tabular}{|c|c|c|c|c|}
\hline Patient & Bacteria & Culture site & $\begin{array}{l}\text { Vaginal } \\
\text { swab* }\end{array}$ & $\begin{array}{c}\text { Risk of infection by maternal } \\
\text { history } \dagger\end{array}$ \\
\hline 1 & GBS & Blood & + & None \\
\hline 2 & GBS & Blood & + & Amnionitis \\
\hline 3 & GBS & Blood & + & None \\
\hline 4 & GBS & Blood & + & None \\
\hline 5 & GBS & Tracheal aspirate & + & PROM \\
\hline 6 & Enterococcus & Blood & + & PROM, amnionitis \\
\hline 7 & Enterococcus & Blood & - & PROM \\
\hline 8 & Streptococcus viridans & Blood & - & PROM, amnionitis \\
\hline 9 & Haemophilus influenzae & Blood & + & PROM \\
\hline 10 & Enterobacter cloacae & Blood/tracheal aspirate & - & $\begin{array}{l}\text { PROM, culture-proven urinary tract } \\
\text { infection }\end{array}$ \\
\hline
\end{tabular}

* Vaginal swab positive if the pathogen isolated from the neonate was detected.

+ Cases of amnionitis are proven by histologic examination. PROM, premature rupture of membranes. 
Table 2. Acute-phase proteins (C3. CRP). complement activation products. and blood cell coumt in healthy and infected neonates

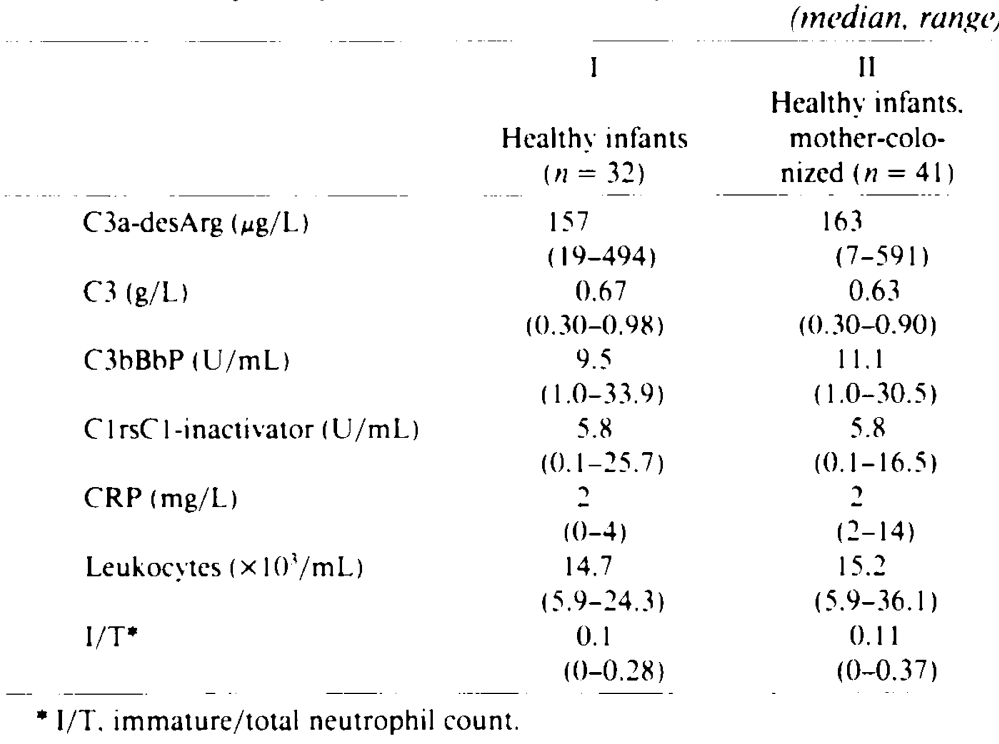

III
Infants
colonized
$(n=15)$
199
$(69-368)$
0.67
$(0.30-0.90)$
12.5
$(1.0-24.9)$
6.3
$(0.1-13.3)$
2
$(2-15)$
13.6
$(6.9-23.6)$
0.08
$(0.02-0.42)$

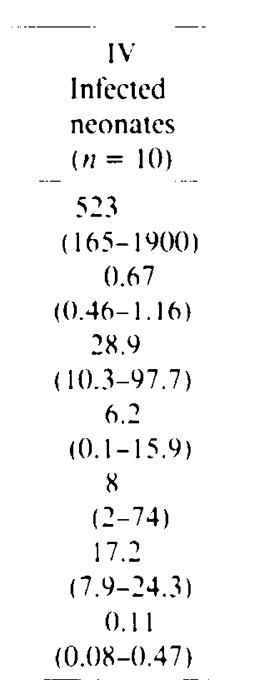

Significant
differences
between groups
I and IV $(p)$
0.0001
NS
0.0013
NS
0.0080
NS
NS

groups. Concentrations of $\mathrm{C} 3 \mathrm{bBbP}$ in GBS-colonized neonates and in infants with colonized mothers did not differ from that in newborns without colonization. However, neonates with proven infection showed a significant increase in C3bBbP levels $(p=0.0013)$. Cl rsCl-inactivator levels did not differ among the four groups. There was a positive correlation $(r=0.76)$ between C3a-desArg levels and C3bBbP levels (Fig. 1), but there was no significant correlation between $\mathrm{C} 3 \mathrm{a}$-desArg and $\mathrm{C} 1$ rsCl-inactivator $(r=0.103)$ or $C 3$ levels $(r=0.136)$, indicating that $C 3 a-$ desArg is activated via the alternative pathway independent of C 3 concentration.

In the first few hours after birth, white blood cell counts, immature/total neutrophil counts, and differential blood cell counts showed no significant differences between the four groups (Table 2).

The values of $\mathrm{C} 3, \mathrm{C} 3 \mathrm{a}$-desArg, C3bBbP, and $\mathrm{Cl}$ rsCl-inactivator in healthy neonates did not change significantly within the first $7 \mathrm{~d}$ after birth.

Figure 2 gives an example of the course of $\mathrm{C} 3 \mathrm{a}$-desArg levels in one infant with severe early-onset infection under antibiotic

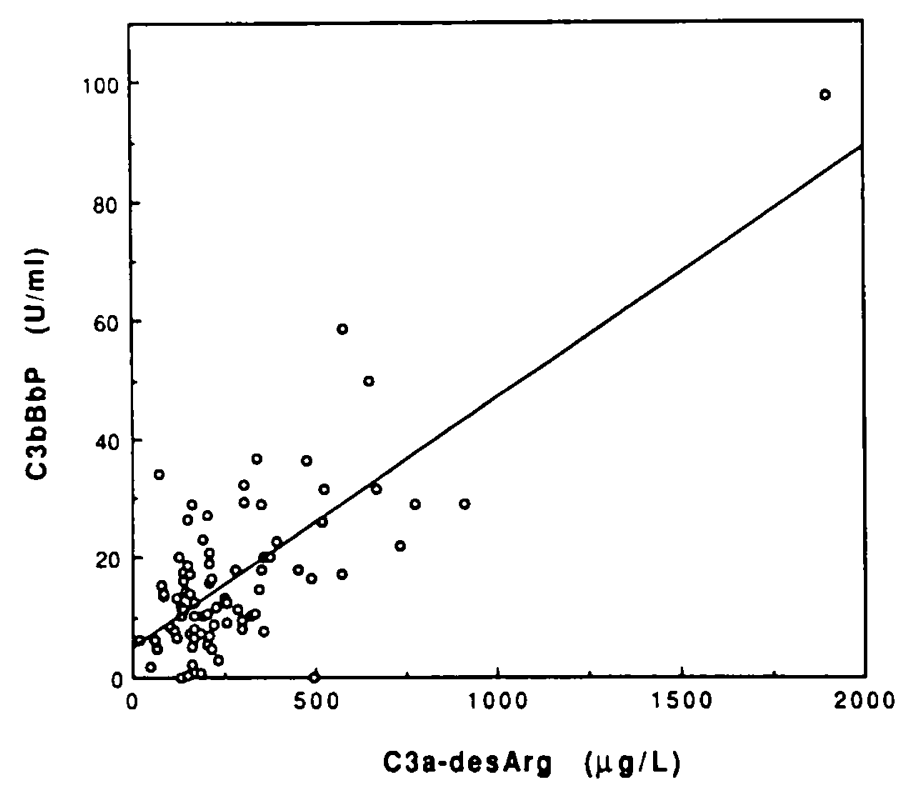

Fig. 1. Correlation plot between C3a-desArg and C3bBbP levels in EDTA plasma of the whole patient population; $r=0.76$. Samples were obtained within the first $6 \mathrm{~h}$ of life. treatment. CRP is shown as a comparison. The initial values represent a maximum for $\mathrm{C} 3 \mathrm{a}$-desArg and a considerable increase for CRP. On d 3, C3a-desArg decreased to only slightly elevated values, whereas CRP levels reached a maximum peak. $\mathrm{C} 3 \mathrm{bBbP}$ levels showed an initial maximum peak and then decreased from d 3 to $\mathrm{d} 9$ parallel to $\mathrm{C} 3 \mathrm{a}$-desArg levels. There were no significant changes in classical pathway activation.

\section{DISCUSSION}

Complement components are synthesized at an early stage of fetal development. In cord blood of full-term neonates, the concentrations of the components $\mathrm{C} 1, \mathrm{C} 2, \mathrm{C} 4$, and $\mathrm{C} 6$ are about $50 \%$ of maternal levels $(10,24)$. Because levels of maternal complement rise during pregnancy, this corresponds to a higher percentage compared with normal adults (7). Plasma concentration of $C 7$ in neonates is about $70 \%$ of the adult value (25), and levels of C8 and C9 are about 10 to $25 \%$ of the value in normal adults (3). C3 levels in full-term neonates are about 50 to $75 \%$ of maternal levels $(26,27)$ or 60 to $80 \%$ of normal adults $(28)$. In agreement with the decreased levels of various complement components, the $\mathrm{CH} 50$ (i.e. the functional activity of the classical pathway components) and APH50 in neonates are decreased to about $50 \%$ of the maternal values (26).

It has been proposed that the reduced levels of complement components in neonates are a major cause for the enhanced susceptibility to infections, because complement is required for optimal chemotaxis (29) and opsonic activity $(30,31)$. However. measurements of the circulating native complement components or of the CH50 do not provide accurate information about the extent of complement activation, because both activation and reduced synthesis result in diminished levels of complement components. On the other hand, acute-phase reactions may lead to increased synthesis, thereby compensating for the consumption of complement components. Measurement of the complement-split product $\mathrm{C} 3 \mathrm{a}$-desArg and the complexes $\mathrm{C} 3 \mathrm{bBbP}$ and C1rsCl-inactivator by ELISA techniques provide a sensitive method of detecting complement activation. The levels of these proteins only depend on the degree of activation: they are not influenced by release or synthesis in an acute-phase reaction. This could be demonstrated by the level of $\mathrm{C} 3$ and its activation product $\mathrm{C} 3 \mathrm{a}$-desArg (Table 2). Whereas C3 levels remained within the normal range even in severe early onset infection, the concentrations of $\mathrm{C} 3 \mathrm{a}$-desArg were significantly higher in these patients. C3 levels in the healthy neonates were lower than in adults (1), as reported previously $(27,29)$. Studies of complement levels in neonatal infection gave conflicting results. Some authors 
EARLY ONSET INFECTION
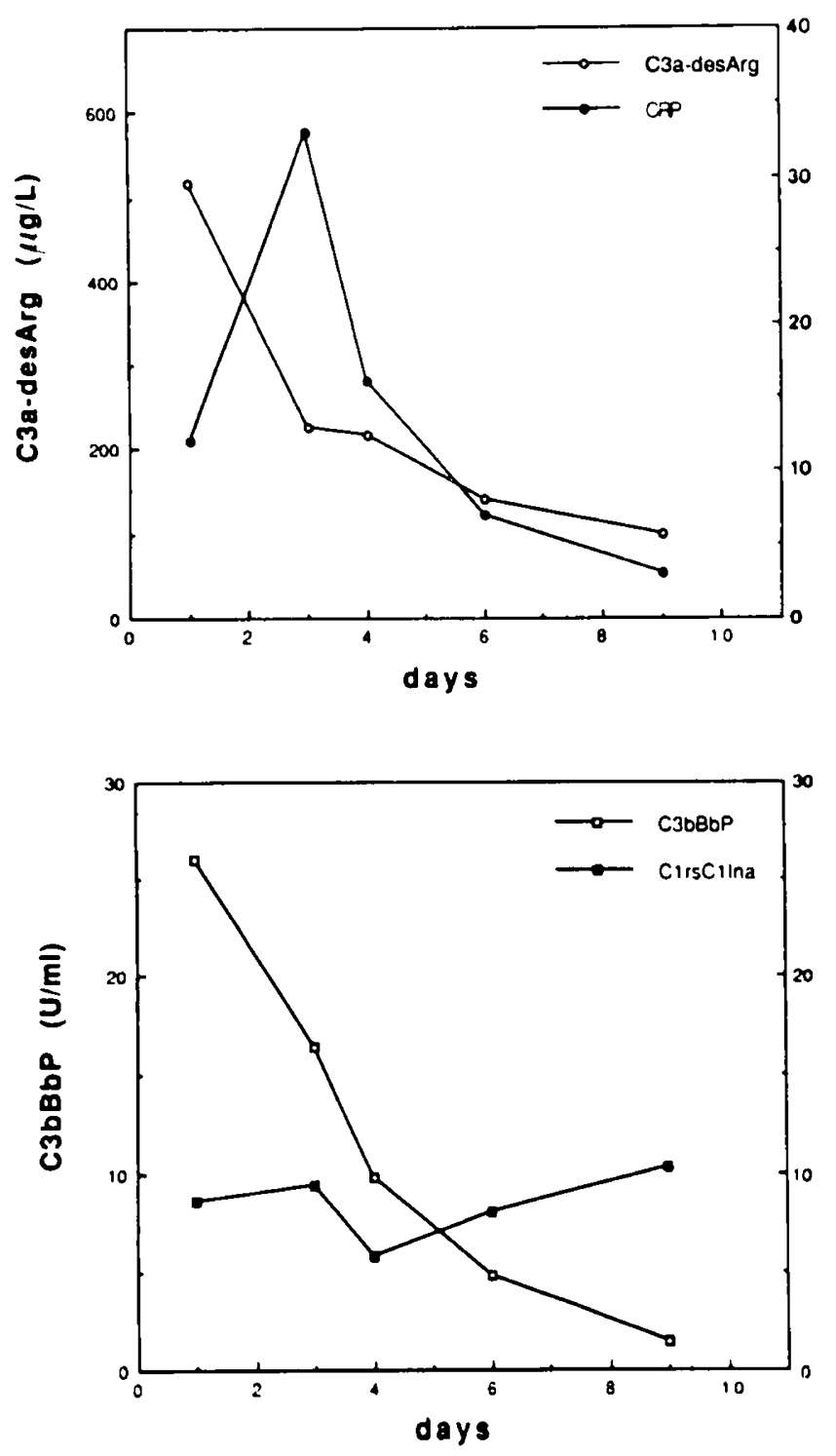

Fig. 2. CRP levels and concentration of the complement activation products $\mathrm{C} 3 \mathrm{a}$-desArg, $\mathrm{C} 3 \mathrm{bBbP}$, and $\mathrm{Cl}$ rsCl-inactivator are given in a patient with early-onset infection over a period of $9 \mathrm{~d}$.

have reported decreased $(32,33)$ or increased (14) C3 levels in neonatal infection, but in most studies, no significant differences in $\mathrm{C} 3$ levels between infected and healthy neonates were observed (34-37). Our results are in agreement with these findings. We found no significant differences in $\mathrm{C} 3$ levels among the four groups. However, significant differences in the activation products C3a-desArg and C3bBbP were noted. In nine out of 10 neonates with early-onset infection C3a-desArg was increased within the first few hours of life (Table 2), due to both gramnegative and gram-positive pathogens (Table 1). This increase was paralleled by an increase in $\mathrm{C} 3 \mathrm{bBbP}$ (i.e. alternative pathway activation). These findings are in agreement with elevated C3d levels found in cases of amnionitis even in premature infants (38). Elevation of activation products occurred in a few neonates without proven infection. This remains unexplained, inasmuch as both the infants and their mothers were apparently healthy. Nevertheless, viral infection without striking clinical signs and without change in routine laboratory testing (leukocyte and thrombocyte count, CRP) that might theoretically be able to initiate complement activation could not be excluded. The activation products $\mathrm{C} 3 \mathrm{a}$-des $\mathrm{Arg}$ and $\mathrm{C} 3 \mathrm{bBbP}$ were similar in healthy neonates (Table 1) and in adults (23). Moreover, severe neonatal infection increased C3a-desArg to the level observed in septicemic adults (23). Thus, lower levels of the $C 3$ component in neonates do not appear to limit the generation of C3a-desArg and $\mathrm{C} 3 \mathrm{bBbP}$.

The cell walls of gram-positive bacteria activate complement in the absence of antibody via the alternative pathway, gramnegative bacteria via both pathways. Activation of complement at the site of inflammation results in the production of several factors: fragments of $\mathrm{C} 3$ are deposited on the surface of the E bacteria opsonizing them for subsequent phagocytosis. The small peptides C3a and C5a can act as chemotactic factors. C5a attracts of neutrophils to the site of inflammation and stimulates them to

$\mathcal{\delta}$ release active mediators such as reactive oxygen metabolites, eicosanoids, and enzymes. The C5b-9 complex provides the lytic activity of complement. These events contribute to destruction of the intruders and provide an important and efficient mechanism of host defense. The apparently sufficient C3-activation does not, however, allow any conclusion on further functional aspects. Zach et al. (39) reported defects in thiolester reactivity of the C3b fragment in premature neonates. This might be of critical importance for membrane binding and opsonization of bacterial pathogens. In our study, the terminal complement cascade was not investigated. There are several reports about diminished concentrations of factors of the terminal complement complex (3). Recently, it has been shown that supplemental $C 9$ enhanced the capacity of neonatal sera to kill a pathogenic strain of Escherichia coli (40), suggesting that C9 deficiency may be one of the factors that predispose neonates to develop $E$. coli $\overline{\overline{\mathbf{E}}}$ sepsis. In all 10 neonates who suffered from severe early-onset infec$\supseteq$ tion, the initial choice of antibiotic treatment proved to be w successful. Under these conditions, complement activation prod들 ucts of the alternative pathway showed their highest plasma concentration in the first sample taken, and later samples de$\checkmark$ creased to near-normal or normal values. This typical course is $\bar{v}$ demonstrated for one patient in Figure 2 and is in contradiction to the course of CRP, an acute-phase reactant that is used routinely. CRP showed a delayed increase that continued even after initiation of successful treatment, as previously shown in the literature (41). This might be explained by the fact that the increase of CRP needs enhanced production of this protein, which needs time, whereas complement activation products result from a cascade system that is ready to react immediately after external stimulation. Thus, activation products of the alternative pathway provide very early parameters of severe neonatal infection.

\section{REFERENCES}

1. Alper CA. Colten HR, Roren FS, Rebson AR, Macuab GM, Gear JJS 1972 Homozygous deficiency of $\mathrm{C} 3$ in a patient with repeated infections. Lancet 2:1179-1181

2. Borzy MS, Gewruz A. Wolff L. Houghton D, Lovrien E 1988 Inherited C3 deficiency with recurrent infections and glomerulonephritis. Am J Dis Child 142:79-83

3. Ballow M 1974 Developmental aspects of complement components in the newborn. Clin Exp Immunol 18:257-266

4. Davis CA, Vallota EH, Farristal J 1979 Serum complement levels in infancy: age-related changes. Pediatr Res 13:1043-1046

5. Drew JH, Arrogave CM 1980 The complement system of the newborn infant. Biol Neonate 37:209-217

6. Sawyer MK. Forman ML, Kuplic LS, Stiehm ER 1971 Developmental aspects of the human complement system. Biol Neonate 19:148-162

7. Adinolfi M 1977 Human complement. Onset and site of the synthesis during fetal life. Am J Dis Child 131:1015-1023

8. Hugli TE 1984 Structure and function of the anaphylatoxins. Semin Immunopathol 7:193-219

9. Hugli TE 1986 Biochemistry and biology of anaphylatoxins. Complement 3:111-208

10. Fireman P, Zuchowski DA. Taylor PM 1965 Development of human complement system. J Immunol 103:25-3!

11. Mills EL. Björksten B. Quie PG 1979 Deficient alternative complement pathway activity in newborn sera. Pediatr Res 13:1341-1344

12. Strunk RC, Fenton LJ, Gaines JA 1979 Alternative pathway of complement activation in full term and premature infants. Pediatr Res 13:641-643 
13. Johnson U. Truedsson L, Gustavii B 1983 Complement components in 100 newborns and their mothers determined by electroimmunoassay. Acta $\mathrm{Pa}$ thol Microbiol Scand (C) 91:147-150

14. Miyano A, Nakayama M, Fujita T, Kitajima H. Imai S, Shimizu A 1987 Complement activation in fetuses: assessment by the levels of complement components and split products in cord blood. Diagn Clin Immunol 5:369372

15. Guillois B, Berthou C, Awad H, Bendaoud B, Guillemin G, Alix D. Youinou P 1989 The importance of C3d estimation in the diagnosis of generalized bacterial infections in newborn infants. Acta Paediatr Scand 78:369-372

16. Götze O, Müller-Eberhard HJ 1971 The C3-activator system: an alternative pathway of complement activation. J Exp Med 139:44-57

17. Laurell AB, Johnson U, Martensson U, Sjöholm AG 1978 Formation of complexes composed of $\mathrm{C} 1 \mathrm{r}, \mathrm{Cls}$ and $\mathrm{Cl}$ inactivator in human serum on activation of C1. Acta Pathol Microbiol Scand (C) 86:299-305

18. Ballard JL. Novak KK. Driver M 1979 A simplified score for assessment of fetal maturation of newly born infants. J Pediatr 95:769-774

19. Islam AKMS 1977 Rapid recognition of group B streptococci. [letter] Lancet $1: 256-257$

20. Zilow G. Naser W, Rutz R, Burger R 1989 Quantitation of the anaphylatoxin $\mathrm{C} 3 \mathrm{a}$ in the presence of $\mathrm{C} 3$ by a novel sandwich ELISA using monoclonal antibody to a C3a neoepitop. J Immunol Meth 121:261-268

21. Burger R. Zilow G. Bader A. Friedlein A, Naser W 1988 The $C$ terminus of the anaphylatoxin $\mathrm{C} 3 \mathrm{a}$ generated upon complement activation represents a neoantigenic determinant with diagnostic potential. J Immunol 141:553558

22. Burger R. Bader A, Kirschfink M, Rother U. Schrod L, Wörner I. Zilow G 1987 Functional analysis and quantification of the complement derived anaphylatoxin $\mathrm{C} 3 \mathrm{a}$ with a monoclonal antibody. Clin Exp Immunol 68:703-

23. Zilow G, Sturm JA, Rother U. Kirschfink M 1990 Complement activation and the prognostic value of $\mathrm{C} 3 \mathrm{a}$ in patients at risk of adult respiratory distress syndrome. Clin Exp Immunol 79:151-157

24. Adinolfi M 1970 Levels of two components of complement (C4 and C3) in human fetal and newborn sera. Dev Med Child Neurol 12:306-308

25. Adinolfi M. Beck S 1976 Human complement $\mathrm{C} 7$ and $C 9$ in fetal and newborn sera. Arch Dis Child 50:562-564

26. Anderson DC. Hughes BJ, Edwards MS, Buffone GJ. Baker CJ 1983 Impaired chemotaxigenesis by type III group B streptococci in neonatal sera: relation- ship to diminished concentration of specific anticapsular antibody and abnormalities of serum complement. Pediatr Res 17:496-502

27. Balla G, Karmazsin L 1983 Evolution of serum C3. IgG, IgA, and IgM levels of healthy mothers and their mature newborns during the early neonatal period. Acta Paediatr Acad Sci Hung 24:4l-51

28. Johnston RB. Altenburger KM. Atkinson AW. Curry RH 1979 Complement in the newborn infant. Pediatrics 65:781-786

29. Adamkin D, Stitzel A. Urmson J. Farnett MI, Post E, Spitzer R 1978 Activity of the alternative pathway of complement in the newborn infant. J Pediatr 93:604-608

30. Hill HR 1985 Host defenses in the neonate: prospects for enhancement. Semin Perinatol 9:2-11

31. Baker CJ. Edwards MS, Webb BJ, Kasper DL 1982 Antibody-independent classical pathway mediated opsonophagocytosis of type la. group B streptococcus. J Clin Invest 69:394-404

32. Pelet B 1980 C3, factor B, alpha-1-antitrypsin in neonatal septicemia with sclerema. Arch Dis Child 55:782-788

33. Beatty DW, Ryder CR. Heese HDV 1986 Complement abnormalities during an epidemic of group B meningococcal infection in children. Clin Exp Immunol 64:465-470

34. McMurray DN, Rey H 1981 Immunological sequelae of intrauterine infection. Clin Exp Immunol 44:389-395

35. Shapiro R. Beatty DW, Woods DL. Sinclair-Smith CC. Malan AF 1983 Complement activity in the cord blood of term neonates with the amniotic fluid infection syndrome. S Afr Med J 63:86-87

36. Singh RP. Thirupuram S. Sharma VK. Natarajan R 1990 Complement components in neonatal sepsis. Ann Trop Paediatr 10:35-37

37. Lassiter HA. Tanner JE. Cost KM. Steger S. Vogel RL 1991 Diminished IgG but not complement $\mathrm{C} 3$ or $\mathrm{C} 4$ or factor $\mathrm{B}$. precedes nosocomial bacterial sepsis in very low weight neonates. Pediatr Infect Dis J 10:663-668

38. Kitajima H, Fujimura M. Takeuchi T. Miyano A. Nakayama M, Fujita T. Imai S. Shimizu A 1990 Effect of amnionitis on the complement system of preterm infants. Early Hum Dev 21:59-69

39. Zach TL. Hostetter MK 1989 Biochemical abnormalities of the third component of complement in neonates. Pediatr Res 26:116-120

40. Lassiter HA, Watson SW, Seifring ML. Tanner JE 1992 Complement factor 9 deficiency in serum of human neonates. J Infect Dis 166:53-57

41. Mathers NJ. Pohlandt F 1987 Diagnostic audit of C-reactive protein in neonatal infection. Eur J Pediatr 146:147-151 